\title{
Mixed Hardwood and Sugarcane Bagasse Biochar as Potting Mix Components for Container Tomato and Basil Seedling Production
}

\author{
Ping $\mathrm{Yu}^{1}$, Qiansheng $\mathrm{Li}^{2}{ }^{2}$, Lan Huang ${ }^{3}{ }^{(D)}$, Genhua Niu ${ }^{4}\left(\mathbb{D}\right.$ and Mengmeng Gu ${ }^{2} * \mathbb{C}$ \\ 1 Department of Horticultural Sciences, Texas A\&M University, 2133 TAMU, College Station, TX 77843, USA; \\ yuping520@tamu.edu \\ 2 Department of Horticultural Sciences, Texas A\&M AgriLife Extension Service, 2134 TAMU, College Station, \\ TX 77843, USA; qianshengli@tamu.edu \\ 3 Institute of Urban Agriculture, Chinese Academy of Agricultural Sciences, Chengdu 610000, China; \\ huanglan_92@163.com \\ 4 Texas A\&M AgriLife Research and Extension Center at Dallas, 17360 Coit Road, Dallas, TX 75252, USA; \\ gniu@ag.tamu.edu \\ * Correspondence: mgu@tamu.edu; Tel.: +1-979-845-8567
}

Received: 30 September 2019; Accepted: 3 November 2019; Published: 5 November 2019

\begin{abstract}
To investigate the potential of biochar as a propagation mix component, three experiments were conducted. A phytotoxicity test was conducted with water extract of sugarcane bagasse biochar (SBB), SBB mixes $(10 \%, 30 \%, 50 \%$, and $70 \%$ SBB with $30 \%$ perlite $(\mathrm{P})$ and the rest being peat moss (PM); by vol.), mixed hardwood biochar (HB) mixes (10\%, 30\%, 50\%, $70 \%$ and $100 \%$ HB with PM; by vol.), PM, P, $70 \% \mathrm{PM}: 30 \% \mathrm{P}$, and a commercial propagation mix (exp. 1). None of the mixes caused phytotoxicity. The same biochar mixes (except $100 \% \mathrm{HB}$ ) were used for the seedling growth test (exp. 2). Both tomato and basil seedlings grown in all of the biochar mixes (except $50 \% \mathrm{HB}$ ) had significantly lower fresh weight, dry weight and growth index (GI) compared to a commercial propagation mix. Six seedlings from each biochar mix were transplanted into a commercial growing mix and grown for four weeks (exp. 3). Tomato seedlings from all biochar mixes (except 30\% SBB) had similar SPAD (Soil-Plant Analyses Development) and GI to the control. Basil seedlings from all HB mixes, $70 \%$ and $100 \%$ SBB mixes had similar GI to the control. In conclusion, $70 \% \mathrm{HB}$ could be amended with PM for tomato and basil seedling production without negative effects on plant biomass.
\end{abstract}

Keywords: biochar; greenhouse; production; seedlings

\section{Introduction}

Peat moss (PM) has been widely used as a horticultural substrate due to its ideal physical and chemical properties, such as low bulk density (BD), high water holding capacity, high aeration ratio, and high cation exchange capacity [1-3]. Domestic PM sales in the US were $0.25 \mathrm{M} \mathrm{m}^{3}$ in 2016 and almost 91\% PM was sold to the horticultural industry [4]. The marketable PM estimated value in the US was $\$ 13.0$ million in 2018 [4]. Peat moss mining, however, has been questioned due to the peatland ecosystem disturbance and/or loss, and its environmental consequences. Hence, alternative materials such as pretreated manure composts and processed timber by-products have been introduced as PM replacements [5].

Biochar, a carbon-rich by-product from biomass pyrolysis, has potential for substituting PM as greenhouse growing media [6]. Pyrolysis biochar is generated from biomass thermo-chemical decomposition in oxygen-depleted or oxygen-limited atmosphere [7-9]. Biochar has been considered as a sustainable material because it can be derived from various sources, such as pinewood $[3,10,11]$, 
green waste [12], wood, sugarcane bagasse [13], straw [14-18], bark [19], rice hull [20], and wheat straw [16,21]. For the same reason, biochar properties can vary widely [22]. Most greenhouse trials have used biochar derived from lignin-based materials, which has appropriate properties for plant growth [12]. Graber [23] reported that citrus wood biochar has potential to improve pepper and tomato plant growth in a systematic way, increasing the leaf area, canopy and yield. Guo [6] found that incorporating pinewood biochar with PM-based commercial substrate increased poinsettia growth. Huang's [24] study showed that mixing hardwood biochar with two different composts could lead to similar or better plant growth in basil and tomato plants in comparison to those in PM-based commercial substrates. Tian [12] confirmed that the total biomass could be significantly increased (by $22 \%$ ) by mixing green waste biochar with a PM-based substrate. When adding biochar in composted green waste, the shoot fresh weight, shoot dry weight, root fresh weight, and root dry weight of Calathea insignis were increased by $57.3 \%, 79.7 \%, 64.5 \%$, and $82.0 \%$, respectively [25]. Similar works had also been reported on Easter lily $[6,26,27]$. The biochar from red oak feedstock mixed with vermiculite also increased hybrid poplar total biomass and shoot biomass [28].

Biochar that affects greenhouse seedling production or subsequent seedling growth has seldom been reported. As biochar from different resources has varied properties, some may have adverse effects on plant growth due to possible phytotoxicity [29]. Phytotoxicity assessment is critical for successful soil/soilless amendment with bioenergy by-products such as biochar [30], and the germination test is a reliable procedure for different types of biochar phytotoxicity examinations [30]. We conducted this study to test the phytotoxicity of two biochars from different raw materials and to explore the use of the two biochars in subsequent container seedling production.

\section{Materials and Methods}

\subsection{Experiment 1: Media Phytotoxicity and Property Test}

Sugarcane bagasse biochar (SBB, American Biocarbon LLC White Castle, Louisiana, USA) was mixed with P (30\%, by vol., Kinney Bonded Warehouse, Tyler, TX, USA) at rates of $10 \%, 30 \%$, $50 \%, 70 \%$ and $100 \%$ (by vol.), with the rest being PM (Voluntary purchasing Group Inc., Bonham, Texas, USA) when SBB and P did not add up to $100 \%$. No P or PM were added to $100 \%$ SBB mix. Mixed hardwood biochar (HB, Proton Power Inc. Lenouir City, Tennessee, USA) was mixed with $\mathrm{PM}$ at rates of $10 \%, 30 \%, 50 \%, 70 \%$ and $100 \%$ (by vol.), and no $\mathrm{P}$ was incorporated. Another mix was formulated by mixing PM and $\mathrm{P}$ at a 7:3 ratio (70\%PM:30\%P; by vol.). Peat moss, $\mathrm{P}$, and a commercial propagation substrate (CS, BM2, Berger, Saint-Modest, Quebec, Canada) were also included in this study. The commercial propagation mix contained $70-80 \%$ of fine sphagnum moss with the rest being fine $\mathrm{P}$ and fine vermiculite. The United States Department of Agriculture-Agricultural Research Service, Sugarcane Research Unit (Houma, Louisiana, USA) provided the SBB, which was produced with proprietary methods, and the Proton Power Inc. (Lenouir City, Tennessee, USA) provided HB, which was a by-product from fast pyrolysis of mixed hardwood. Sugarcane bagasse biochar had a $\mathrm{pH}$ of 5.9 and $\mathrm{HB}$ had a $\mathrm{pH}$ of 10.1. The electrical conductivity (EC) of the two biochars were $753 \mu \mathrm{S} / \mathrm{cm}$ (SBB) and 1,058 $\mu \mathrm{S} / \mathrm{cm}(\mathrm{HB})$, respectively [31]. Because SBB had a similar $\mathrm{pH}$ to PM (SBB 5.9, PM 5.0, Table 1) and the SBB particle size was smaller (mean $0.17 \mathrm{~mm}$, resulting in low air space (AS)) [31], when formulating mixes with $\mathrm{SBB}, 30 \% \mathrm{P}$ was incorporated to increase the $\mathrm{pH}$ of the AS and the mix. As HB had a higher $\mathrm{pH}(10.1)$ than PM (5.0), and the HB particle size was larger $(67.3 \%>2.0 \mathrm{~mm}$, resulting in high AS) [25], no P was incorporated when formulating mixes with HB. The properties of all the components used in this study are shown in Table 1. 
Table 1. The $\mathrm{pH}$, electrical conductbity (EC), total porosity (TP), container capacity (CC), air space (AS) and bulk density (BD) of substrate components used in this study.

\begin{tabular}{ccccccc}
\hline Substrate Component $^{\mathbf{z}}$ & $\mathbf{p H}$ & $\mathbf{E C}(\boldsymbol{\mu S} / \mathbf{c m})$ & $\mathbf{T P}(\%)$ & $\mathbf{C C}(\mathbf{\%})$ & $\mathbf{A S}(\mathbf{\%})$ & $\mathbf{B D}\left(\mathrm{g} / \mathbf{c m}^{\mathbf{3}}\right)$ \\
\hline SBB & 5.9 & 753 & $74 \pm 2$ & $71 \pm 1$ & $3 \pm 1$ & $0.11 \pm 0.00$ \\
HB & 10.1 & 1,058 & $87 \pm 1$ & $66 \pm 1$ & $20 \pm 1$ & $0.13 \pm 0.00$ \\
PM:P (70:30) & 5.6 & 162 & $79 \pm 1$ & $62 \pm 1$ & $16 \pm 1$ & $0.09 \pm 0.00$ \\
CS & 6.8 & 745 & $75 \pm 2$ & $66 \pm 1$ & $9 \pm 1$ & $0.09 \pm 0.00$ \\
P & 7.3 & 57 & $92 \pm 1$ & $59 \pm 1$ & $34 \pm 0$ & $0.05 \pm 0.00$ \\
PM & 5.0 & 179 & $69 \pm 1$ & $58 \pm 1$ & $11 \pm 0$ & $0.11 \pm 0.00$ \\
\hline
\end{tabular}

Note: ${ }^{\mathrm{z}} \mathrm{SBB}=$ Sugarcane bagasse biochar; $\mathrm{HB}=$ Mixed hardwood biochar; $\mathrm{CS}=$ Commercial propagation substrate; $\mathrm{P}=$ Perlite; $\mathrm{PM}=$ Peat moss. Numbers in parens indicated the ratio of different components, by vol.

All of the mixes were subjected to a phytotoxicity test with Gravel's method [32]. Briefly, water extract was obtained by soaking the mixes with $100 \mathrm{~mL}$ deionized (DI) water and shaking for 24 hours. The mixtures were filtered through $11 \mathrm{~cm}$-diameter VWR Grade 415 filter paper (quantitative) (VWR International, LLC, Randor, Pennsylvania, USA) and $3 \mathrm{~mL}$ extract was used to saturate another filter paper placed in a petri dish. Deionized water was used as the control in this experiment. Twenty-five basil (Ocimum basilicum) (Johnny's Selected Seeds, Winslow, Maine, USA) seeds were placed in each petri dish. The emergence percentage (EP) of basil seeds was calculated after incubating the petri dishes at $25{ }^{\circ} \mathrm{C}$ in the dark for 7 days by using the following formula: $\mathrm{EP}=$ (no. of emerged seedlings/total no. of seeds) $\times 100 \%$. This experimental design was a complete randomized design with six replicates.

All of the physical properties of the media, including bulk density (BD), total porosity (TP), air space (AS) and container capacity (CC), were determined using the North Carolina State University Horticultural Substrates Laboratory Porometers [33]. The substrate $\mathrm{pH}$ and EC were measured by using a handheld $\mathrm{pH}-\mathrm{EC}$ meter (Hanna Instrument, Woonsocket, Rhode Island, USA) according to the pour-through extraction method [34]. Three replications of each substrate were measured.

\subsection{Experiment 2: Biochar as Amendments for Greenhouse Media for Seedling Production}

Tomato (Solanum lycopersicum 'Red Robin'TM') (Fred C. Gloeckner \& Company Inc., Harrison, NY, USA) and basil (Ocimum basilicum) (Johnny's Selected Seeds, Winslow, ME, USA) seeds were soaked in DI water for $24 \mathrm{~h}$ before sowing in 72-cell (cell depth: $5 \mathrm{~cm}$; cell top length and width: $4 \mathrm{~cm}$; volume: $55 \mathrm{ml}$ ) plug trays with one seed per cell on 16 February, 2019.

Five SBB:P substrates were formulated by mixing SBB at 10\%, 30\%, 50\%, 70\%, and 100\% (by vol.) with 30\% P (Kinney Bonded Warehouse, Tyler, TX, USA, except for the 100\% SBB) and the rest being Peat moss (PM) (Voluntary purchasing Group Inc., Bonham, TX, USA) when SBB and P did not add up to $100 \%$. Four HB:PM substrates were formulated by mixing HB at $10 \%, 30 \%, 50 \%$, and $70 \%$ (by vol.) with PM and a commercial propagation mix (CS, BM2, Berger, Saint-Modest, QC, Canada) was used as the control.

All of the mixes had four replications (10 cells per replication), which were arranged in completely randomized blocks in the greenhouse located on Texas A\&M University campus, College Station, TX, USA. The average greenhouse temperature, relative humidity and dew point were $22.8^{\circ} \mathrm{C}, 79.7 \%$ and $18.3^{\circ} \mathrm{C}$, respectively. Before the true leaves (tomato or basil) emerged, the trays were irrigated with DI water. After the true leaves emerged, trays were irrigated with $50 \mathrm{mg} \mathrm{N} \cdot \mathrm{L}^{-1}$ (20N-4.3P-16.6K) Peters@Professional (Everris NA Inc, Dublin, Ohio, USA) nutrient solution.

At the end of this experiment (27 March, 2019), the height of four randomly-selected seedlings from each mix was measured from the medium surface to the highest point of the plants, and the widest width (width 1 ) and its perpendicular width (width 2) were measured. The growth index (GI) was calculated as: GI= Height $/ 2+$ (width 1+ width 2)/4 [6]. Leave greenness was indicated by Soil-Plant Analyses Development (SPAD) readings. (SPAD 502 Plus Chlorophyll Meter, Spectrum Technologies, Inc., Plainfield, Illinois USA). For each mix, shoots (stalk and leaf) and roots of four seedlings were harvested separately. The total fresh weight (TFW) was determined at harvest by adding up the fresh 
weights of the stalk and leaf. Shoot dry weight (SDW) and root dry weight (RDW, after being washed) were determined after drying at $80^{\circ} \mathrm{C}$ in an oven until a constant weight was reached. Roots were washed and root length, surface area, root average diameter, and the number of tips were measured by using a root scanner (WinRHIZO, Regent Instruments Inc., Canada). The total dry weight (TDW) was calculated by adding up the SDW and RDW.

\subsection{Experiment 3: The Subsequent Growth Evaluation of Seedlings Produced in Biochar-Amended Media}

At the end of the second experiment, six seedlings in each mix with similar GI were selected and transplanted into 6-inch azalea pots (depth: $10.8 \mathrm{~cm}$; top diameter: $15.5 \mathrm{~cm}$; bottom diameter: 11.3 $\mathrm{cm}$; volume: $1330 \mathrm{ml}$ ) with a commercial growing substrate (CS1, Jolly Gardener, Oldcastle Lawn \& Garden Inc. Atlanta, Georgia, USA). The commercial growing mix contained 55\% (by vol.) aged pine bark, with the other ingredients being Canadian sphagnum PM, P and vermiculite. The growth index was measured biweekly and the SPAD was measured on 2 April, 2019. After four weeks of growing, plants' leaves and stems were harvested separately, and the stem DW (SDW), leaf DW (LDW) and flower or fruit DW (FDW) were determined after drying in an oven at $80^{\circ} \mathrm{C}$ until a constant weight was reached. The total dry weight (TDW) was calculated by adding up the SDW, LDW and FDW.

\subsection{Statistical Analysis}

The experiments were set up in a completely randomized block design. Data were analyzed with one-way analysis of variance using JMP Statistical Software (version Pro 12.2.0; SAS Institute, Cary, North Carolina, USA) and means were separated using Dunnett's test when treatments were significantly different from control at $p<0.05$.

\section{Results}

\subsection{Media Phytotoxicity and Properties}

The water extract of the commercial propagation mix and the $\mathrm{P}$ had significantly higher EP than DI water (the control). All other biochar-amended mixes, the PM:P mix, and PM had a similar EP compared to the control (Figure 1).

The $\mathrm{pH}$ of HB-amended mixes had positive linear correlations with the biochar incorporation rate, while SBB-amended mixes showed quadratic correlations. The electrical conductivity (EC) of all biochar-amended mixes increased with an increasing biochar incorporation rate, and had quadratic correlations (Figure 2). All of the mixes' TPs were within the recommended range (50\% to $85 \%$ ). The TPs of the HB-amended mixes had positive linear correlations with the biochar incorporation rate; however, the SBB-amended mixes showed quadratic correlations. All of the SBB-amended mixes' CCs were also within the recommended range ( $45 \%$ to $65 \%$ ), except for $100 \%$ SBB mixes $(71 \%)$. The CC of $10 \%$ HB-amended mixes was within the recommended range $(62 \%)$, while all the other HB-amended mixes' CCs were slightly beyond the range (68\% the highest). The air space of all the biochar-amended mixes was within the recommended range (10\% to 30\%), except for the $50 \%, 70 \%$, and $100 \%$ SBB-amended mixes. The air space of all SBB-amended mixes decreased as the biochar incorporation rate increased; however, the AS of all HB-amended mixes increased with the biochar rate. The bulk density (BD) of both SBB- and HB-amended mixes were similar (Figure 3). 


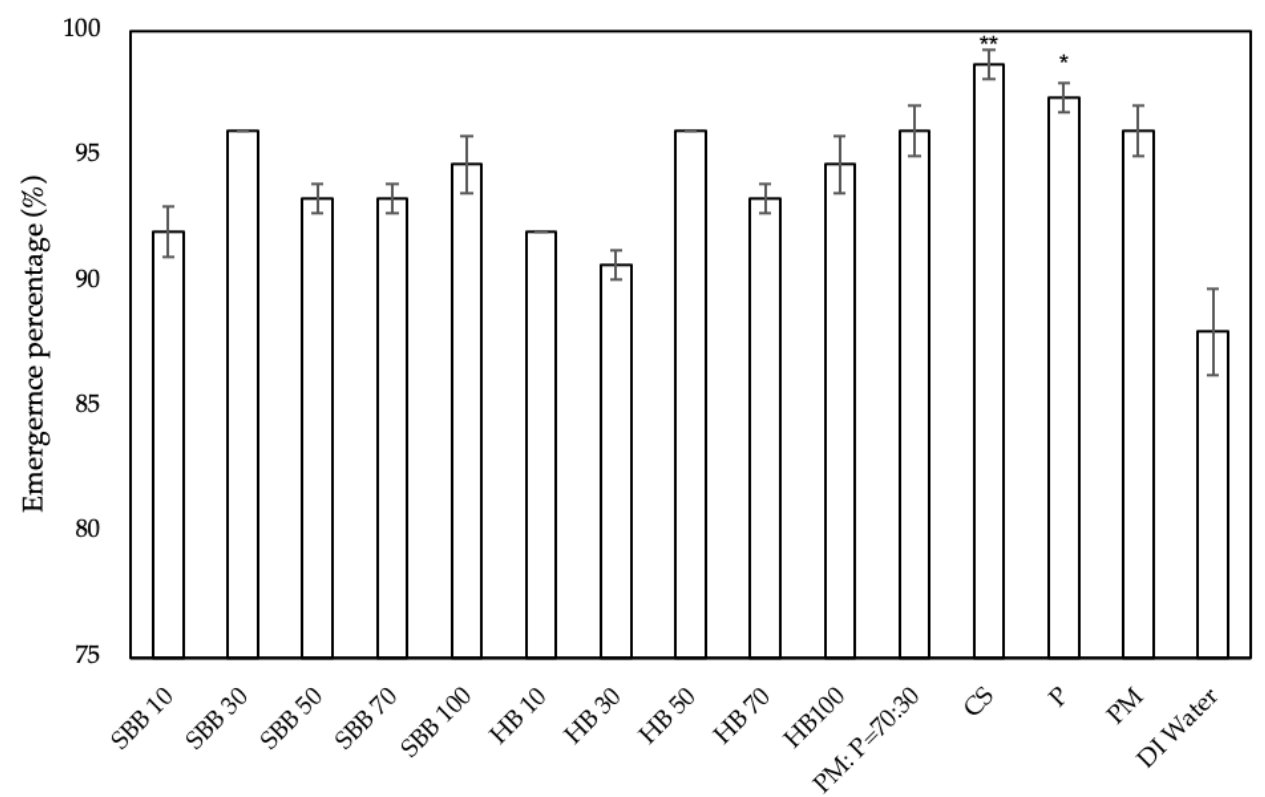

Figure 1. The emergence percentage of basil seedlings in the water extract of different mixes. ${ }^{*}{ }^{* *}$ indicate a significant difference from the control (DI water) using Dunnett's test at $p \leq 0.05$ and $p \leq$ 0.01 , respectively. $\mathrm{SBB}=$ sugarcane bagasse biochar; $\mathrm{HB}=$ mixed hardwood biochar; $\mathrm{CS}=$ commercial propagation substrate; SBB $(10 \%, 30 \%, 50 \%, 70 \%$ and $100 \%$; by vol.) incorporated with $30 \%$ perlite with the rest being peat moss; $\mathrm{HB}(10 \%, 30 \%, 50 \%$ and $70 \%$; by vol.) incorporated with peat moss.
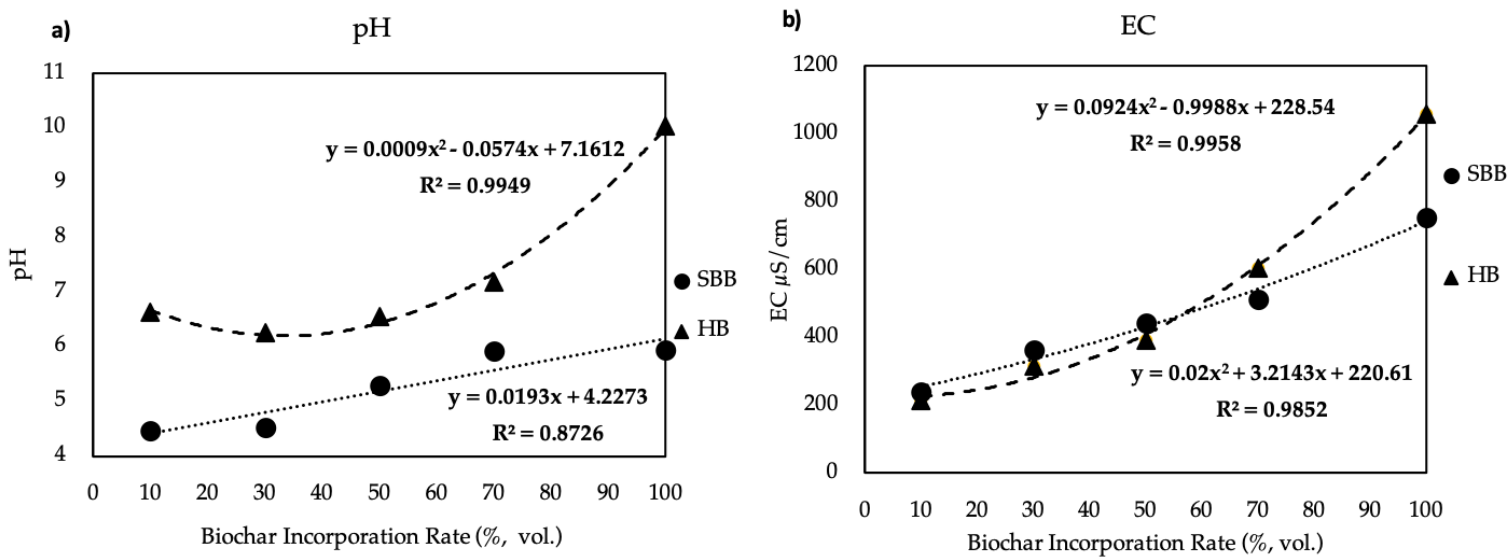

Figure 2. The correlation between $\mathrm{pH}$ (a) and electrical conductivity (EC) (b) and biochar incorporation rate. $\mathrm{SBB}=$ sugarcane bagasse biochar; $\mathrm{HB}=$ mixed hardwood biochar. $\mathrm{SBB}(10 \%, 30 \%, 50 \%, 70 \%$ and $100 \%$; by vol.) incorporated with $30 \%$ perlite with the rest being peat moss; $\mathrm{HB}(10 \%, 30 \%, 50 \%$ and $70 \%$; by vol.) incorporated with peat moss. 

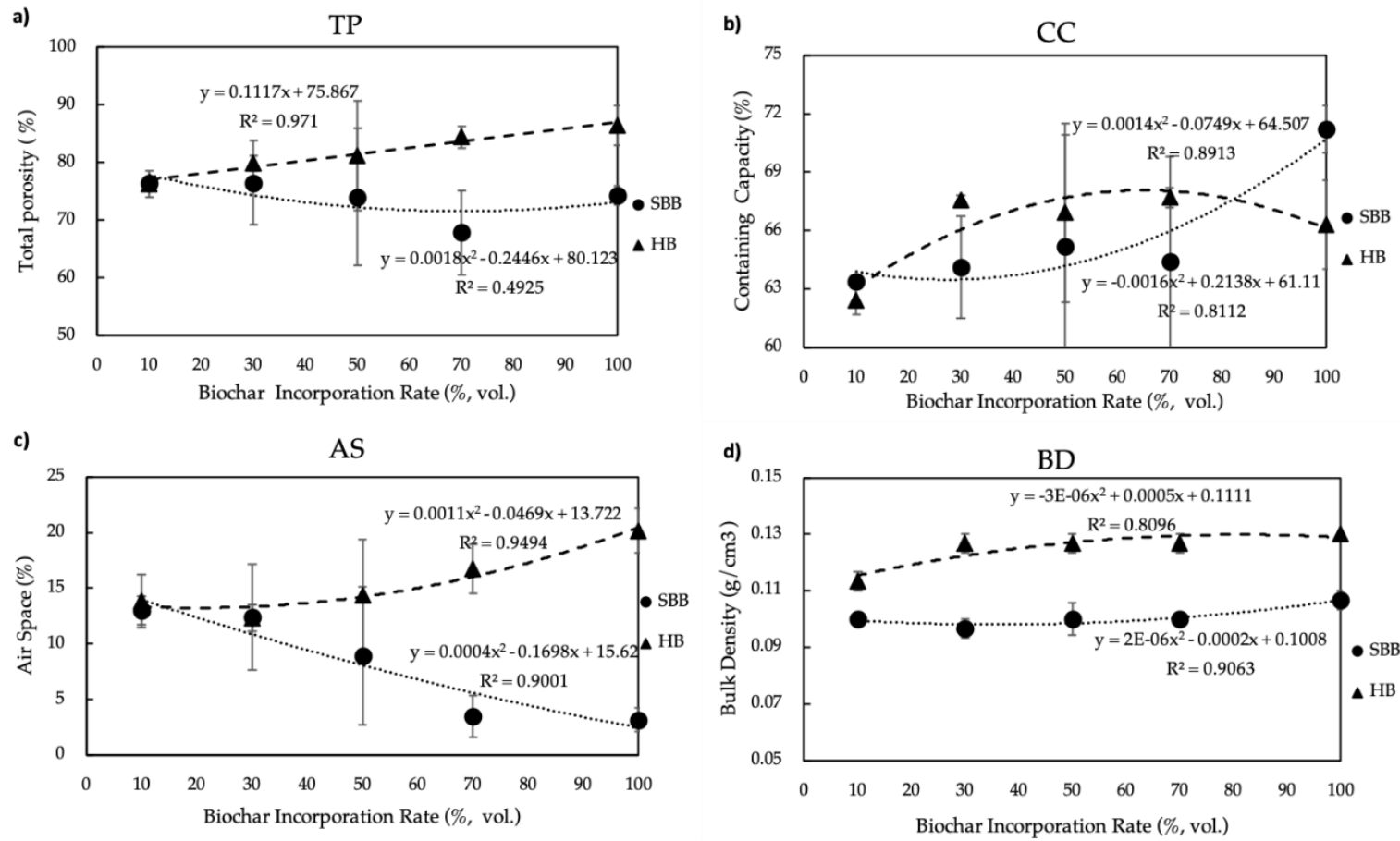

Figure 3. The correlation between substrate total porosity (TP, a), containing capacity $(\mathbf{C C}, \mathbf{b})$, air space (AS, c) and bulk density (BD, d) and biochar incorporation rate. SBB = sugarcane bagasse biochar; $\mathrm{HB}$ $=$ mixed hardwood biochar. SBB $(10 \%, 30 \%, 50 \%, 70 \%$ and $100 \%$; by vol.) incorporated with $30 \%$ perlite with the rest being peat moss; $\mathrm{HB}(10 \%, 30 \%, 50 \%$ and $70 \%$; by vol.) incorporated with peat moss.

\subsection{Biochars as Amendment for Greenhouse Media for Seedling Production}

\subsubsection{Tomato Seedling Growth}

The total fresh weight (TFW), total dry weight (TDW) and GI of SBB-amended mixes had positive linear correlations with the biochar incorporation rate, while HB-amended mixes showed quadratic correlations (Figure 4a-c). All TFWs, TDWs and GIs in biochar-amended mixes were significantly lower than the control, except for those in 50\% HB-amended mixes. Tomato seedlings grown in all SBB-amended mixes had similar SPAD to the control (except 100\% SBB, Figure 4d); however, seedlings grown in all HB-amended mixes had significantly lower SPAD (except $10 \% \mathrm{HB}$ ).

All tomato seedlings grown in biochar-amended mixes had significantly shorter root lengths than the control (except 30\% HB, Table 2). Except for seedlings grown in 50\% SBB, 30\% HB and 50\% HB, all tomato seedlings grown in biochar-amended mixes had significantly smaller root surface areas than the control. Seedlings grown in all biochar-amended mixes had similar or wider root diameters compared to the control; however, they all had fewer root tips (except 30\% $\mathrm{HB}$ and 50\% $\mathrm{HB}$ ). 

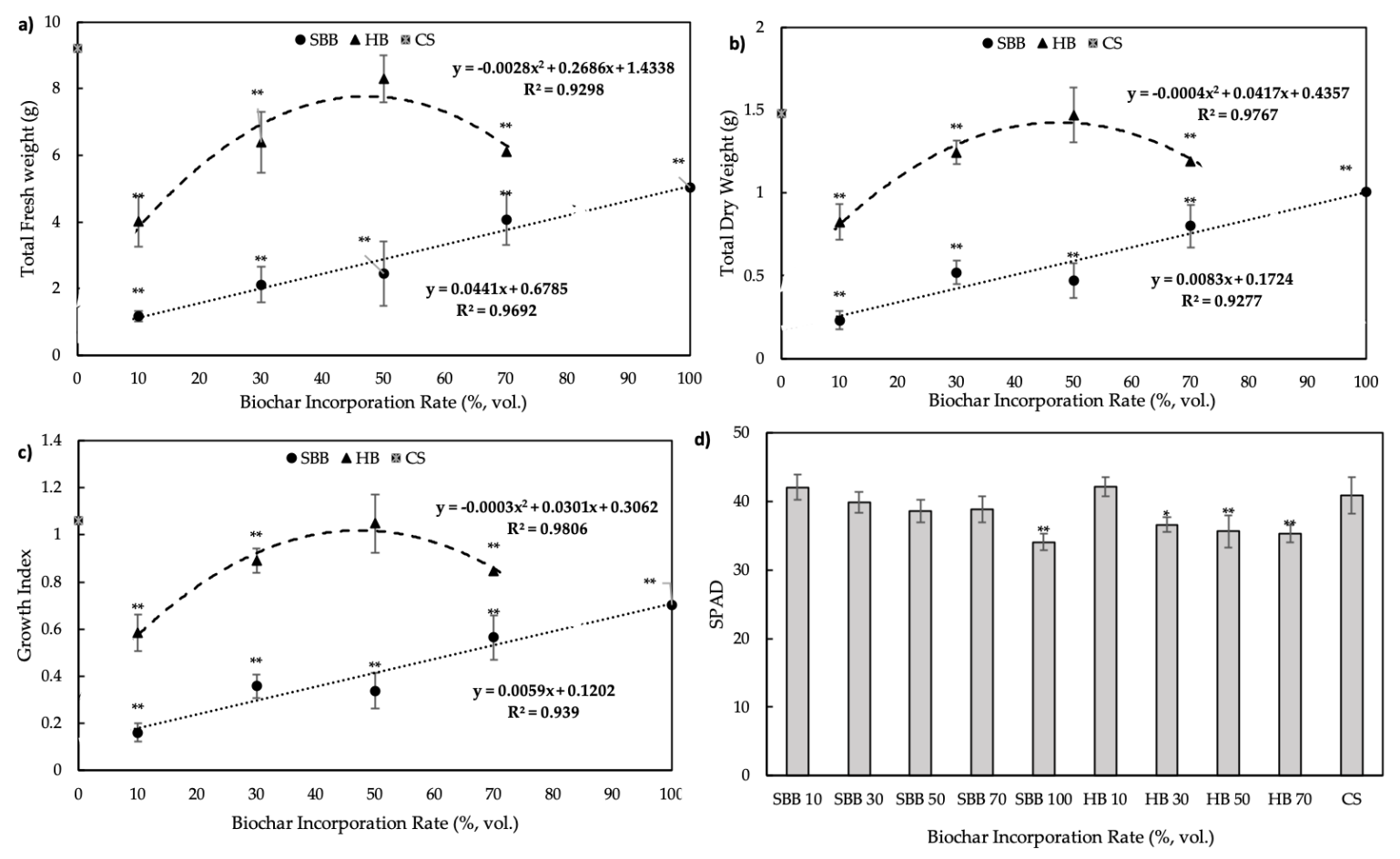

Figure 4. The correlations between total fresh weight (TFW, a), total dry weight (TDW, b), growth index (GI, c) and biochar incorporation rate and the soil-Plant Analyses development (SPAD) (d) of tomato seedlings grown in biochar-amended mixes. SBB = sugarcane bagasse biochar; $\mathrm{HB}=$ mixed hardwood biochar; CS = commercial propagation substrate. SBB $(10 \%, 30 \%, 50 \%, 70 \%$ and $100 \%$; by vol.) incorporated with $30 \%$ perlite with the rest being peat moss; $\mathrm{HB}(10 \%, 30 \%, 50 \%$ and $70 \%$; by vol.) incorporated with peat moss. $(* * *$ indicated significant difference from the control using Dunnett's test at $p \leq 0.05$ and $p \leq 0.01$, respectively).

Table 2. Root growth of tomato seedlings grown in different mixes $\left({ }^{*},{ }^{* *}\right.$ indicate a significant difference from the control using Dunnett's test at $p \leq 0.05$ and $p \leq 0.01$, respectively).

\begin{tabular}{ccccc}
\hline Mixes $^{\mathbf{z}}$ & Root Length $\mathbf{( \mathbf { c m } )}$ & $\begin{array}{c}\text { Root Surface Area } \\
\left(\mathbf{c m}^{\mathbf{2}} \mathbf{c}\right.\end{array}$ & $\begin{array}{c}\text { Average Diameter } \\
(\mathbf{m m})\end{array}$ & Number of Tips \\
\hline SBB:PM:P(10:60:30) & $125 \pm 10^{* *}$ & $27 \pm 3^{* *}$ & $0.69 \pm 0.05^{* *}$ & $410 \pm 45^{* *}$ \\
SBB:PM:P(30:40:30) & $209 \pm 8^{* *}$ & $37 \pm 1^{* *}$ & $0.57 \pm 0.01$ & $625 \pm 60^{* *}$ \\
SBB:PM:P(50:20:30) & $277 \pm 27^{* *}$ & $55 \pm 4$ & $0.64 \pm 0.03^{*}$ & $789 \pm 120^{*}$ \\
SBB:PM:P(70:0:30) & $259 \pm 26^{* *}$ & $49 \pm 4^{*}$ & $0.60 \pm 0.02$ & $657 \pm 26^{* *}$ \\
SBB:PM:P(100:0:0) & $281 \pm 50^{*}$ & $52 \pm 7^{*}$ & $0.60 \pm 0.03$ & $718 \pm 91^{*}$ \\
HB:PM(10:90) & $243 \pm 36^{* *}$ & $46 \pm 5^{* *}$ & $0.62 \pm 0.04$ & $648 \pm 30^{*}$ \\
HB:PM(30:70) & $350 \pm 26$ & $64 \pm 4$ & $0.58 \pm 0.04$ & $817 \pm 64$ \\
HB:PM(50:50) & $278 \pm 31^{* *}$ & $56 \pm 3$ & $0.66 \pm 0.05^{*}$ & $1055 \pm 148$ \\
HB:PM(70:30) & $271 \pm 21^{* *}$ & $50 \pm 2^{*}$ & $0.60 \pm 0.02$ & $746 \pm 47^{* *}$ \\
Control & $432 \pm 35$ & $68 \pm 4$ & $0.50 \pm 0.01$ & $1147 \pm 141$ \\
\hline
\end{tabular}

Note: ${ }^{\mathrm{z}} \mathrm{SBB}=$ sugarcane bagasse biochar; $\mathrm{HB}=$ mixed hardwood biochar; $\mathrm{P}=$ perlite; $\mathrm{PM}=$ peat moss; $\mathrm{Control}=$ commercial propagation substrate. Numbers in parentheses indicate the ratio of different components, by vol.

\subsubsection{Basil Seedling Growth}

The total fresh weight (TFW), total dry weight (TDW) and GI of seedlings in SBB-amended mixes had positive linear correlations with the biochar incorporation rate, while seedlings in HB-amended mixes showed quadratic correlations (Figure 5a-c). All TFWs (except 30\% and 50\% HB), TDWs and GIs (except 50\% HB) in biochar-amended mixes were significantly lower than the control. Basil seedlings grown in all biochar-amended mixes had similar or higher SPAD than the control (except 100\% SBB, Figure 5d). 

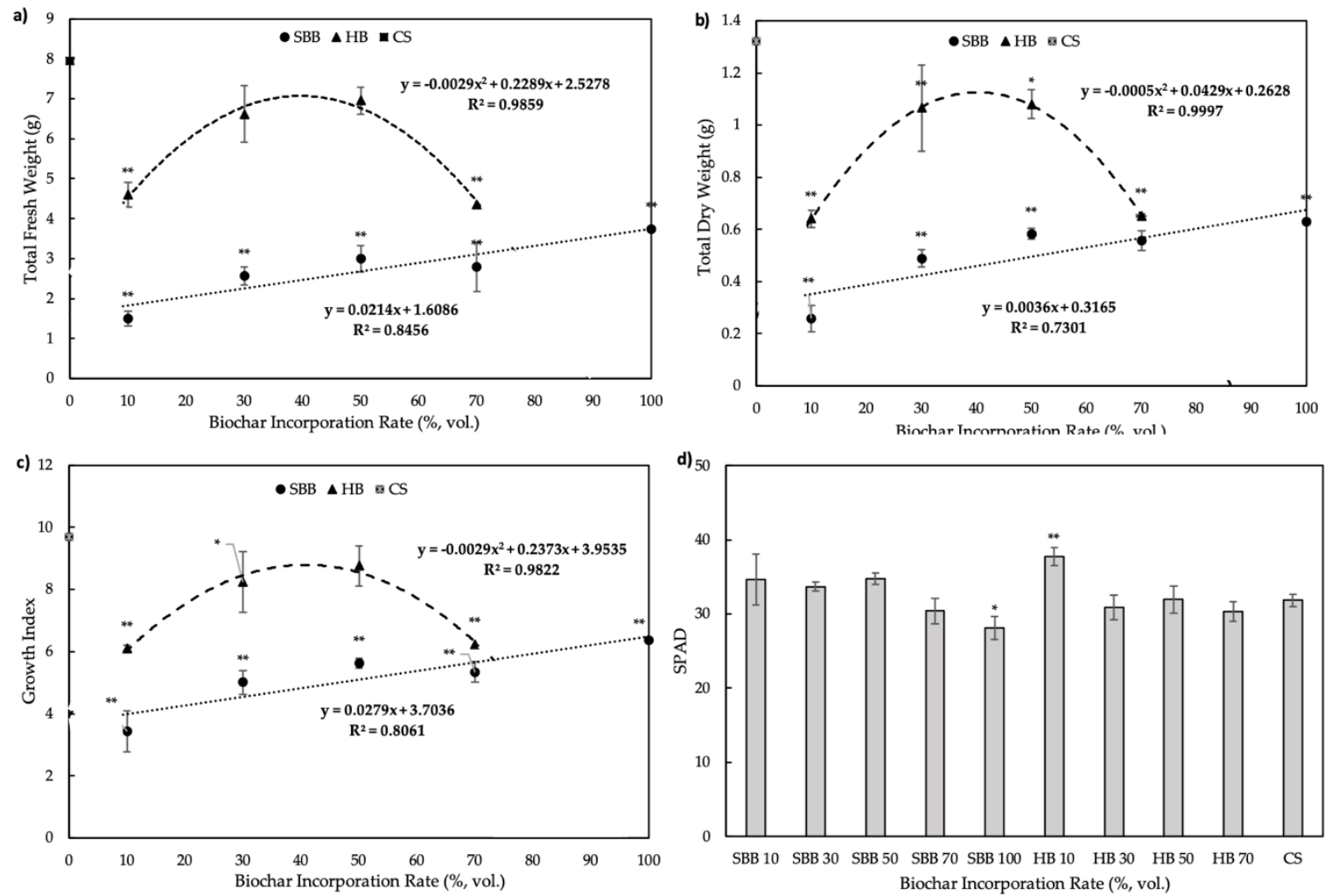

Figure 5. The correlations between total fresh weight (TFW, a), total dry weight (TDW, b), growth index (GI, c) and biochar incorporation rate and the SPAD (d) of basil seedlings grown in biochar-amended mixes. $\mathrm{SBB}=$ sugarcane bagasse biochar; $\mathrm{HB}=$ mixed hardwood biochar; $\mathrm{CS}=$ commercial propagation substrate. SBB $(10 \%, 30 \%, 50 \%, 70 \%$ and $100 \%$; by vol.) incorporated with $30 \%$ perlite with the rest being peat moss; $\mathrm{HB}\left(10 \%, 30 \%, 50 \%\right.$ and $70 \%$; by vol.) incorporated with peat moss. $\left({ }^{*}, * *\right.$ indicate a significant difference from the control using Dunnett's test at $p \leq 0.05$ and $p \leq 0.01$, respectively).

All basil seedlings grown in biochar-amended mixes had significantly shorter root lengths, smaller root surface areas and fewer root tips than the control (Table 3); however, they all had similar root diameters.

Table 3. Root growth of basil seedlings grown in different mixes $\left({ }^{*}, * *\right.$ indicate a significant difference from the control using Dunnett's test at $p \leq 0.05$ and $p \leq 0.01$, respectively).

\begin{tabular}{|c|c|c|c|c|}
\hline Mixes $^{z}$ & Root Length (cm) & $\begin{array}{l}\text { Root Surface Area } \\
\qquad\left(\mathrm{cm}^{2}\right)\end{array}$ & $\begin{array}{l}\text { Average Diameter } \\
(\mathrm{mm})\end{array}$ & Number of Tips \\
\hline SBB:PM:P(10:60:30) & $121 \pm 13^{* *}$ & $16 \pm 1^{* *}$ & $0.43 \pm 0.03$ & $480 \pm 42^{* *}$ \\
\hline SBB:PM:P(30:40:30) & $295 \pm 523^{* *}$ & $34 \pm 11^{* *}$ & $0.37 \pm 0.01$ & $819 \pm 88^{* *}$ \\
\hline SBB:PM:P(50:20:30) & $433 \pm 23^{* *}$ & $51 \pm 6^{* *}$ & $0.37 \pm 0.01$ & $1408 \pm 235^{* *}$ \\
\hline SBB:PM:P(70:0:30) & $617 \pm 92^{* *}$ & $72 \pm 22^{* *}$ & $0.37 \pm 0.01$ & $1204 \pm 118^{* *}$ \\
\hline SBB:PM:P(100:0:0) & $841 \pm 95^{*}$ & $97 \pm 15^{* *}$ & $0.37 \pm 0.02$ & $1584 \pm 163^{* *}$ \\
\hline HB:PM(10:90) & $331 \pm 29^{* *}$ & $40 \pm 7^{* *}$ & $0.39 \pm 0.01$ & $873 \pm 45^{* *}$ \\
\hline HB:PM(30:70) & $757 \pm 67^{* *}$ & $88 \pm 19^{* *}$ & $0.37 \pm 0.01$ & $1758 \pm 177^{* *}$ \\
\hline HB:PM(50:50) & $793 \pm 145^{* *}$ & $96 \pm 35^{* *}$ & $0.39 \pm 0.01$ & $1761 \pm 167^{* *}$ \\
\hline HB:PM(70:30) & $690 \pm 44^{* *}$ & $85 \pm 6^{* *}$ & $0.39 \pm 0.01$ & $1446 \pm 194^{* *}$ \\
\hline Control & $1181 \pm 67$ & $145 \pm 21$ & $0.39 \pm 0.02$ & $3001 \pm 214$ \\
\hline
\end{tabular}

Note: ${ }^{\mathrm{z}} \mathrm{SBB}=$ sugarcane bagasse biochar; $\mathrm{HB}=$ mixed hardwood biochar; $\mathrm{P}=$ perlite; $\mathrm{PM}=$ peat moss; Control = commercial propagation substrate. Numbers in parentheses indicate the ratio of different components, by vol. 


\subsection{The After-Growth Evaluation of Seedlings Produced in Biochar-Amended Media}

\subsubsection{Tomato Plant Growth}

Tomato seedlings from different biochar-amended mixes (except 50\% HB) all had significantly lower GI at transplanting compared to those from the commercial propagation mix (Figure 6a). However, after growing in CS1 for four weeks, all plants from SBB- and HB-amended mixes had similar GI (except 30\% SBB) and SPAD to the control (Figure 6a,b). In addition, tomato plants from all biochar-amended mixes had similar SDW (except 10\% SBB, 30\% SBB and 10\% HB) and leaf dry weight (LDW) (except 10\% SBB) in comparison to the control (Table 4); however, they had significantly lower FDW and TDW than the control.
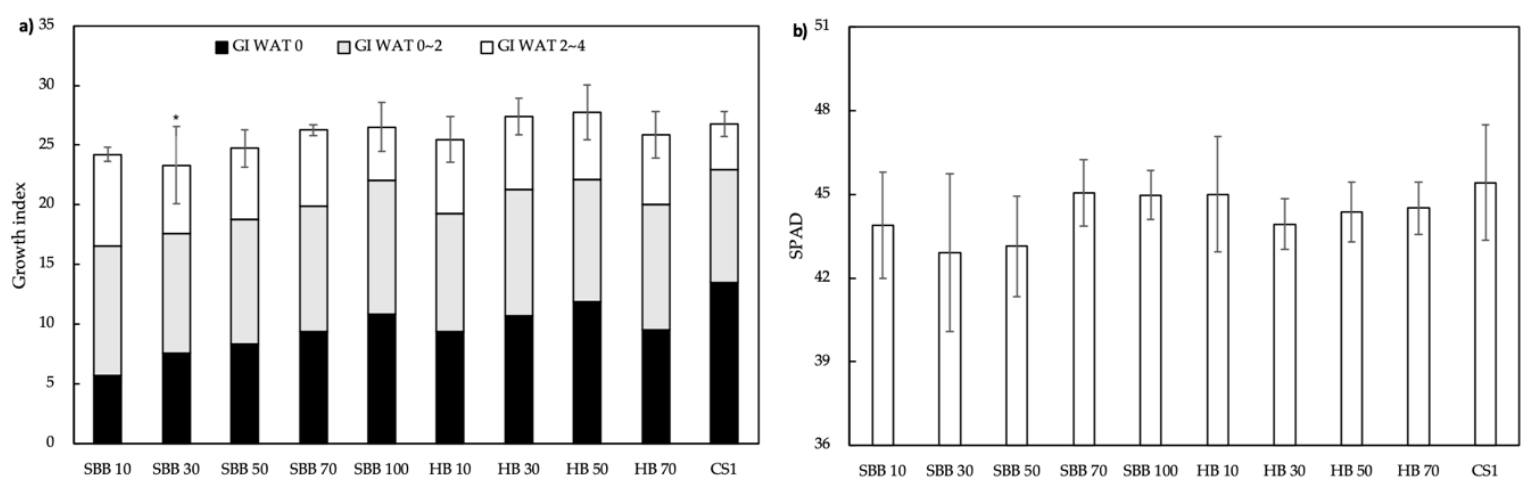

Figure 6. The growth index (a) and SPAD (b) of tomato seedlings from biochar-amended mixes after four weeks in commercial substrate. $\mathrm{SBB}=$ sugarcane bagasse biochar; $\mathrm{HB}=$ mixed hardwood biochar; CS1 = commercial growing substrate. SBB $(10 \%, 30 \%, 50 \%, 70 \%$ and $100 \%$; by vol.) incorporated with $30 \%$ perlite with the rest being peat moss; $\mathrm{HB}(10 \%, 30 \%, 50 \%$ and $70 \%$; by vol.) incorporated with peat moss. ${ }^{*},{ }^{* *}$ indicate a significant difference from the control using Dunnett's test at $p \leq 0.05$ and $p \leq$ 0.01 , respectively).

Table 4. Stalk, leaf, and fruit dry weight (g) of tomato seedlings from biochar-amended mixes after four weeks in the commercial substrate. $\left({ }^{*},{ }^{* *}\right.$ indicate a significant difference from the control using Dunnett's test at $p \leq 0.05$ and $p \leq 0.01$, respectively).

\begin{tabular}{ccccc}
\hline Mixes $^{z}$ & Stalk DW(g) & Leaf DW(g) & Fruit DW(g) & Total DW (g) \\
\hline SBB:PM:P(10:60:30) & $1.7 \pm 0.1^{* *}$ & $6.5 \pm 0.1^{* *}$ & $0.3 \pm 0.0^{* *}$ & $8.5 \pm 0.2^{* * *}$ \\
SBB:PM:P(30:40:30) & $2.0 \pm 0.2^{* *}$ & $7.6 \pm 0.4$ & $1.0 \pm 0.3^{* *}$ & $10.6 \pm 0.9^{* * *}$ \\
SBB:PM:P(50:20:30) & $2.7 \pm 0.2$ & $8.8 \pm 0.5$ & $0.9 \pm 0.1^{* *}$ & $12.5 \pm 0.6^{* * *}$ \\
SBB:PM:P(70:0:30) & $3.2 \pm 0.3$ & $8.7 \pm 0.4$ & $1.3 \pm 0.2^{* *}$ & $13.2 \pm 0.9^{* *}$ \\
SBB:PM:P(100:0:0) & $3.5 \pm 0.2$ & $8.6 \pm 0.2$ & $2.4 \pm 0.2^{* *}$ & $14.5 \pm 0.4^{* *}$ \\
HB:PM(10:90) & $2.4 \pm 0.3^{*}$ & $8.9 \pm 0.5$ & $1.3 \pm 0.2^{* *}$ & $12.6 \pm 0.8^{* * *}$ \\
HB:PM(30:70) & $2.9 \pm 0.3$ & $7.8 \pm 0.4$ & $3.2 \pm 0.7^{* *}$ & $13.9 \pm 1.0^{* *}$ \\
HB:PM(50:50) & $3.2 \pm 0.2$ & $8.1 \pm 0.2$ & $4.0 \pm 0.5^{*}$ & $15.4 \pm 0.5^{*}$ \\
HB:PM(70:30) & $2.6 \pm 0.2$ & $8.4 \pm 0.2$ & $2.0 \pm 0.3^{* *}$ & $12.9 \pm 0.6^{* * *}$ \\
Control & $3.4 \pm 0.1$ & $8.1 \pm 0.5$ & $7.7 \pm 2.3$ & $19.2 \pm 2.1$ \\
\hline
\end{tabular}

Note: ${ }^{\mathrm{z}} \mathrm{SBB}=$ sugarcane bagasse biochar; $\mathrm{HB}=$ mixed hardwood biochar; $\mathrm{P}=$ perlite; $\mathrm{PM}=$ peat moss; Control = commercial growing substrate. Numbers in parentheses indicate the ratio of different components, by vol.

\subsubsection{Basil Plant Growth}

Basil seedlings from different biochar-amended mixes (except $50 \% \mathrm{HB}$ ) all had significantly lower GI at transplanting compared to those from the commercial propagation mix (Figure 7a). However, after growing in CS1 for four weeks, all plants from SBB- and HB-amended mixes (except 10\% SBB, $30 \%$ SBB and 50\% SBB) had similar GI and SPAD (except 30\% SBB, 70\% SBB, 100\% SBB, 30\% HB, 50\% $\mathrm{HB}$ and $70 \% \mathrm{HB}$ ) to the control (Figure $7 \mathrm{a}, \mathrm{b}$ ). In addition, basil plants from all biochar-amended mixes had similar LDW (except 10\% SBB, 30\% SBB and 50\% SBB) and FDW (except 10\% SBB, 30\% SBB, 50\% 
SBB and 10\% HB) in comparison to the control (Table 5). Plants from SBB-amended mixes all had significantly lower SDW and TDW compared to the control; however, plants from HB-amended mixes all had similar SDW (except 10\% HB) and TDW (except 10\% HB and 70\% HB) to the control.
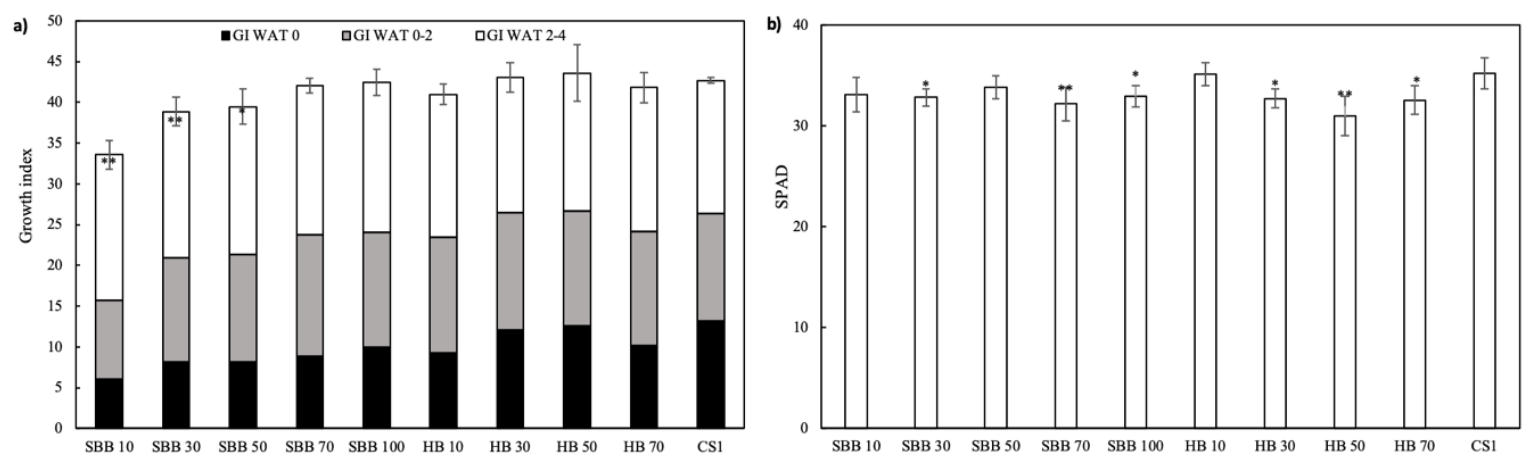

Figure 7. The growth index (a) and SPAD (b) of basil plants transplanted from biochar-amended mixes after four weeks. $\mathrm{SBB}=$ sugarcane bagasse biochar; $\mathrm{HB}=$ mixed hardwood bioTA CS1 = commercial growing substrate. SBB $(10 \%, 30 \%, 50 \%, 70 \%$ and $100 \%$; by vol.) incorporated with $30 \%$ perlite with the rest being peat moss; $\mathrm{HB}\left(10 \%, 30 \%, 50 \%\right.$ and $70 \%$; by vol.) incorporated with peat moss. ${ }^{*}$, ${ }^{* *}$ indicate a significant difference from the control using Dunnett's test at $p \leq 0.05$ and $p \leq 0.01$, respectively).

Table 5. Biomass of basil plants transplanted from biochar-amended mixes after four weeks. (*, ** indicate a significant difference from the control using Dunnett's test at $p \leq 0.05$ and $p \leq 0.01$, respectively).

\begin{tabular}{ccccc}
\hline Mixes $^{z}$ & Stalk DW(g) & Leaf DW(g) & Flower DW (g) & Total DW (g) \\
\hline SBB:PM:P(10:60:30) & $1.8 \pm 0.2^{* *}$ & $4.3 \pm 0.4^{* *}$ & $0.4 \pm 0.1^{* *}$ & $6.4 \pm 0.7^{* * *}$ \\
SBB:PM:P(30:40:30) & $3.3 \pm 0.2^{* *}$ & $6.2 \pm 0.2^{*}$ & $1.1 \pm 0.2^{* *}$ & $10.5 \pm 0.5^{* * *}$ \\
SBB:PM:P(50:20:30) & $3.1 \pm 0.2^{* *}$ & $6.0 \pm 0.4^{* *}$ & $0.8 \pm 0.2^{* *}$ & $9.9 \pm 0.5^{* * *}$ \\
SBB:PM:P(70:0:30) & $3.3 \pm 0.1^{* *}$ & $5.9 \pm 0.2$ & $1.0 \pm 0.1^{* *}$ & $10.2 \pm 0.2^{* * *}$ \\
SBB:PM:P(100:0:0) & $3.9 \pm 0.08^{* *}$ & $6.9 \pm 0.3$ & $1.7 \pm 0.3$ & $12.5 \pm 0.3^{*}$ \\
HB:PM(10:90) & $3.6 \pm 0.1^{* *}$ & $6.4 \pm 0.1$ & $1.2 \pm 0.2^{*}$ & $11.3 \pm 0.3^{* * *}$ \\
HB:PM(30:70) & $4.3 \pm 0.1$ & $7.3 \pm 0.3$ & $2.0 \pm 0.2$ & $13.5 \pm 0.4$ \\
HB:PM(50:50) & $4.4 \pm 0.1$ & $7.3 \pm 0.2$ & $1.9 \pm 0.4$ & $13.6 \pm 0.6$ \\
HB:PM(70:30) & $4.1 \pm 0.3$ & $6.4 \pm 0.6$ & $1.5 \pm 0.5$ & $11.9 \pm 0.7^{* *}$ \\
Control & $4.8 \pm 0.2$ & $7.7 \pm 0.3$ & $2.5 \pm 0.2$ & $14.9 \pm 0.6$
\end{tabular}

Note: ${ }^{\mathrm{z}} \mathrm{SBB}=$ sugarcane bagasse biochar; $\mathrm{HB}=$ mixed hardwood biochar; $\mathrm{P}=$ perlite; $\mathrm{PM}=$ peat moss; Control = commercial growing substrate. Numbers in parentheses indicate the ratio of different components, by vol.

\section{Discussion}

\subsection{Media Phytotoxicity and Substrate Properties}

Prior to incorporating biochar into any soilless substrate, simple germination tests could be used to test the phytotoxicity of biochar, and a phytotoxicity assessment is essential for successful soilless amendment [30]. The soilless petri dish bioassay (also known as the germination test) is a rapid and simple preliminary test recommended by Solaiman to test potential biochar toxicity [35]. In this study, the extracts of $\mathrm{SBB}, \mathrm{HB}$, their mixes with $\mathrm{PM}, \mathrm{PM}, \mathrm{P}, 70 \% \mathrm{PM}: 30 \% \mathrm{P}$ and the commercial propagation mix all showed no phytotoxicity, which is consistent with Taek-Keun's findings [36].

Biochar may or may not have phytotoxic effects on plants depending on the original feedstock and process conditions [30]. For instance, the biochar from hardwood, corn and switchgrass under different process conditions had no effect on germination rate [29], while biochar from olive mill waste was phytotoxic [37]. In this study, the germination rates of all basil seeds in the aqueous extracts of biochar-amended mixes were higher than those in DI water, which indicated no phytotoxicity for the biochar used in this study. This is similar to what had been found in Rogovska's work [29]. However, 
biochar-amended mixes having no effects on seedling germination rates does not necessarily mean they had no inhibition on shoot growth because plant's shoot growth can be inhibited by polycyclic aromatic hydrocarbons present in aqueous extracts [29], or by the poor physical-chemical properties of the mixes [2]. The seedlings grown in SBB-amended mixes had significantly lower DW than the control, which may be due to their low AS [38].

Even though the effects of biochar on substrate properties also varies depending on original feedstock and process conditions [22,30], some biochar types have been proven to improve the physical properties of the growing media [39]. For instance, pinewood biochar from fast pyrolysis of pinewood at $450{ }^{\circ} \mathrm{C}$ can make the substrate better for poinsettia and Easter lily to grow $[6,27]$. Mixed hardwood biochar from fast pyrolysis can also improve the substrate properties for tomato and basil plant growth [24]. Sugarcane bagasse biochar and pinewood biochar improved the growing mix properties for bean and cucurbit seedlings production [31]. The pruning residue biochar produced from pyrolysis at $500^{\circ} \mathrm{C}$ can improve growing media properties for soilless vegetable production [13,39]. The biochar could also replace perlite and has a liming effect when incorporated into a soilless substrate $[40,41]$. These improvements were also observed in this study, especially for HB.

\subsection{Biochar Effects on Plant Growth}

The effects of biochar on plant growth could be positive, null and negative [6,42,43], depending on the types of biochar and the incorporation rates. Incorporating biochar made from woodchips of Pinus densiflora and Quercus acutissima and rice husk at 20\% (by vol.) with growing media, Zelkova serrata seedlings showed better performance than the control in a containerized production system; however, biochar made from crab shell had negative effects on seedling growth [44]. In this study, seedling biomass increased with the SBB (10-100\%) and HB (10-50\%) incorporation rate, which is slightly different from Webber's results [31]. Tomato plants from all biochar-amended mixes had significantly lower FDW (yield), basil plants from biochar-amended mixes (except for $10 \%$ SBB, 30\% SBB and 50\% SBB) had similar LDW (yield) to the control.

Even though the effects of biochar on plant biomass can be variable $[6,42,43]$, the effects of biochar on plant GI is more often positively reported $[6,27,45]$. The GI of plants can be an important parameter for landscape plants such as Magnolia, Ilex, Lagerstroemia and other species [46]. Biochar has also been reported to have positive effects on some ornamental plant GIs, such as poinsettia, Easter lily and "Firework" Gomphrena $[6,27,45]$. In this study, even though seedlings grown in biochar-amended mixes (SBB-, 10\%, 30\% and 70\% HB-amended) had significantly lower TDW than the control, after growing in CS1 for four weeks, plants from biochar-amended mixes (except 30\% SBB for tomato, 10\%, 30\% SBB for basil) all had a similar GI to the control. As landscape plants need more time to grow from seedling to a marketable size, the biochar-amended mixes used in this study might be used more successfully for landscape plants seedling production. More biochar studies on landscape plants should be conducted in the future.

Detailed studies on biochar-root interactions are few [47], but plant roots are the first contacting points to biochar particles. Plants with longer root length, larger surface area and more root tips may be able to obtain more nutrients and grow better [47,48]. In this study, root length, surface area and the number of tips of seedlings grown in biochar-amended mixes (except for 50\%HB-amended) were all shorter, smaller or less than those grown in the control, which can explain why seedlings grown in most biochar-amended mixes did not perform as well as the control.

\section{Conclusions}

The biochar-amended mixes used in this experiment had acceptable BD, CC, AS, and TP (except $50 \%, 70 \%$ and $100 \%$ SBB). The results from this experiment indicated PM mixed with up to $50 \% \mathrm{HB}$ could be used for tomato and basil seedling production in a greenhouse. Both tomato and basil seedlings grown in 50\% HB-amended mixes exhibited greater or similar growth compared to those in a commercial propagation mix, as reflected by similar seedling FW, DW, GI, SPAD and root development. 
Seedlings grown in 70\% HB-amended mixes had significantly lower DW than the control, however, after growing in commercial growing media for four weeks, their DWs were similar to the control. Up to $70 \%$ of $\mathrm{HB}$ could be amended with PM for tomato and basil seedling production without negative effects on plant biomass.

Author Contributions: This work was a product of the combined effort of all the authors. All authors conceptualized and designed the study. P.Y. performed the experiments, collected and analyzed the data, and wrote the manuscript with assistance from all other authors, mainly M.G. L.H., Q.L. and G.N. provided technical advice and assistance when the study was conducted, and revised and improved the manuscript.

Funding: This research received no external funding.

Acknowledgments: The authors would like to thank American Biocarbon LLC White Castle, Louisiana, Proton Power Inc. Lenouir City, Tennessee, for supplying the biochar for the experiment. The work would have been impossible without the support from Elizabeth Pierson and Kevin Crosby, for supplying experimental instruments. The authors would like to thank the Texas A\&M University Open Access to Knowledge Fund (OAKFund, supported by the University Libraries and the Office of the Vice President for Research) for partially covering the open access publishing fees. The authors would also like to thank the Agriculture Women Excited to Share Opinions, Mentoring and Experiences (AWESOME) faculty group of the College of Agriculture and Life Sciences at Texas A\&M University for assistance with editing the manuscript.

Conflicts of Interest: The authors declare no conflict of interest.

\section{References}

1. Chalk, P.; Souza, R.D.F.; Urquiaga, S.; Alves, B.; Boddey, R. The role of arbuscular mycorrhiza in legume symbiotic performance. Soil Biol. Biochem. 2006, 38, 2944-2951. [CrossRef]

2. Nelson, P. Root substrate. In Greenhouse Operation and Management, 7th ed.; Prentice Hall: Upper Saddle River, NJ, USA, 2012; pp. 161-194.

3. Peng, D.H.; Gu, M.M.; Zhao, Y.; Yu, F.; Choi, H.S. Effects of biochar mixes with peat-moss based substrates on growth and development of horticultural crops. Hortic. Sci. Technol. 2018, 36, 501-512. [CrossRef]

4. United States Geological Survey (USGS). PEAT. In Mineral Commodity Summaries; Center, N.M.I., Ed.; USGS: Reston, VA, USA, 2019; pp. 118-119.

5. Alexander, P.; Bragg, N.; Meade, R.; Padelopoulos, G.; Watts, O. Peat in horticulture and conservation: The UK response to a changing world. Mires Peat 2008, 3, 1-10.

6. Guo, Y.; Niu, G.; Starman, T.; Volder, A.; Gu, M. Poinsettia growth and development response to container root substrate with biochar. Horticulturae 2018, 4, 1. [CrossRef]

7. Demirbas, A.; Arin, G. An overview of biomass pyrolysis. Energy Sources 2002, 24, 471-482. [CrossRef]

8. Lehmann, J. A handful of carbon. Nature 2007, 447, 143-144. [CrossRef]

9. Nartey, O.D.; Zhao, B. Biochar preparation, characterization, and adsorptive capacity and its effect on bioavailability of contaminants: An overview. Adv. Mater. Sci. Eng. 2014, 2014, 715398. [CrossRef]

10. Liu, R.; Gu, M.; Huang, L.; Yu, F.; Jung, S.-K.; Choi, H.-S. Effect of pine wood biochar mixed with two types of compost on growth of bell pepper (Capsicum annuum L.). Hortic. Environ. Biotechnol. 2019, 60, 313-319. [CrossRef]

11. Choi, H.-S.; Zhao, Y.; Dou, H.; Cai, X.; Gu, M.; Yu, F. Effects of biochar mixtures with pine-bark based substrates on growth and development of horticultural crops. Hortic. Environ. Biotechnol. 2018, 59, 345-354. [CrossRef]

12. Tian, Y.; Sun, X.; Li, S.; Wang, H.; Wang, L.; Cao, J.; Zhang, L. Biochar made from green waste as peat substitute in growth media for Calathea rotundifola cv. Fasciata. Sci. Hortic. 2012, 143, 15-18. [CrossRef]

13. Webber, C.L., III; White, P.M., Jr.; Spaunhorst, D.J.; Lima, I.M.; Petrie, E.C. Sugarcane biochar as an amendment for greenhouse growing media for the production of cucurbit seedlings. J. Agric. Sci. 2018, 10, 104-115. [CrossRef]

14. Hansen, V.; Hauggaard-Nielsen, H.; Petersen, C.T.; Mikkelsen, T.N.; Müller-Stöver, D. Effects of gasification biochar on plant-available water capacity and plant growth in two contrasting soil types. Soil Tillage Res. 2016, 161, 1-9. [CrossRef]

15. Spokas, K.; Koskinen, W.; Baker, J.; Reicosky, D. Impacts of woodchip biochar additions on greenhouse gas production and sorption/degradation of two herbicides in a Minnesota soil. Chemosphere 2009, 77, 574-581. [CrossRef] [PubMed] 
16. Vaughn, S.F.; Kenar, J.A.; Thompson, A.R.; Peterson, S.C. Comparison of biochars derived from wood pellets and pelletized wheat straw as replacements for peat in potting substrates. Ind. Crop. Prod. 2013, 51, 437-443. [CrossRef]

17. Hansen, V.; Müller-Stöver, D.; Ahrenfeldt, J.; Holm, J.K.; Henriksen, U.B.; Hauggaard-Nielsen, H. Gasification biochar as a valuable by-product for carbon sequestration and soil amendment. Biomass Bioenergy 2015, 72, 300-308. [CrossRef]

18. Spokas, K.A.; Baker, J.M.; Reicosky, D.C. Ethylene: Potential key for biochar amendment impacts. Plant Soil 2010, 333, 443-452. [CrossRef]

19. Hina, K.; Bishop, P.; Arbestain, M.C.; Calvelo-Pereira, R.; Maciá-Agulló, J.A.; Hindmarsh, J.; Hanly, J.; Macias, F.; Hedley, M. Producing biochars with enhanced surface activity through alkaline pretreatment of feedstocks. Soil Res. 2010, 48, 606-617. [CrossRef]

20. Locke, J.C.; Altland, J.E.; Ford, C.W. Gasified rice hull biochar affects nutrition and growth of horticultural crops in container substrates. J. Environ. Hortic. 2013, 31, 195-202.

21. Xu, G.; Zhang, Y.; Sun, J.; Shao, H. Negative interactive effects between biochar and phosphorus fertilization on phosphorus availability and plant yield in saline sodic soil. Sci. Total Environ. 2016, 568, 910-915. [CrossRef]

22. Huang, L.; Gu, M. Effects of biochar on container substrate properties and growth of plants-A Review. Horticulturae 2019, 5, 14. [CrossRef]

23. Graber, E.R.; Harel, Y.M.; Kolton, M.; Cytryn, E.; Silber, A.; David, D.R.; Tsechansky, L.; Borenshtein, M.; Elad, Y. Biochar impact on development and productivity of pepper and tomato grown in fertigated soilless media. Plant Soil 2010, 337, 481-496. [CrossRef]

24. Huang, L.; Niu, G.; Feagley, S.E.; Gu, M. Evaluation of a hardwood biochar and two composts mixes as replacements for a peat-based commercial substrate. Ind. Crop. Prod. 2019, 129, 549-560. [CrossRef]

25. Zhang, L.; Sun, X.-Y.; Tian, Y.; Gong, X.-Q. Biochar and humic acid amendments improve the quality of composted green waste as a growth medium for the ornamental plant Calathea insignis. Sci. Hortic. 2014, 176, 70-78. [CrossRef]

26. Guo, M.; He, Z.; Uchimiya, S.M. Introduction to biochar as an agricultural and environmental amendment. Agric. Environ. Appl. Biochar Adv. Barriers 2016, 63, 1-14.

27. Guo, Y.; Niu, G.; Starman, T.; Gu, M. Growth and development of Easter lily in response to container substrate with biochar. J. Hortic. Sci. Biotechnol. 2018, 94, 80-86. [CrossRef]

28. Headlee, W.L.; Brewer, C.E.; Hall, R.B. Biochar as a substitute for vermiculite in potting mix for hybrid poplar. Bioenergy Res. 2013, 7, 120-131. [CrossRef]

29. Rogovska, N.; Laird, D.; Cruse, R.; Trabue, S.; Heaton, E. Germination tests for assessing biochar quality. J. Environ. Qual. 2012, 41, 1014-1022. [CrossRef] [PubMed]

30. Gell, K.; van Groenigen, J.; Cayuela, M.L. Residues of bioenergy production chains as soil amendments: Immediate and temporal phytotoxicity. J. Hazard. Mater. 2011, 186, 2017-2025. [CrossRef]

31. Webber, C.L., III; White, P.M., Jr.; Gu, M.; Spaunhorst, D.J.; Lima, I.M.; Petrie, E.C. Sugarcane and pine biochar as amendments for greenhouse growing media for the production of bean (Phaseolus vulgaris L.) seedlings. J. Agric. Sci. 2018, 10, 58-68. [CrossRef]

32. Gravel, V.; Dorais, M.; Ménard, C. Organic potted plants amended with biochar: Its effect on growth and Pythium colonization. Can. J. Plant Sci. 2013, 93, 1217-1227. [CrossRef]

33. Fonteno, W.; Hardin, C.; Brewster, J. Procedures for Determining Physical Properties of Horticultural Substrates Using the NCSU Porometer; Horticultural Substrates Laboratory, North Carolina State University: Raleigh, NC, USA, 1995.

34. LeBude, A.; Bilderback, T. Pour-through extraction procedure: A nutrient management tool for nursery crops. North Carol. Coop. Ext. 2009. AG-717-W.

35. Solaiman, Z.M.; Murphy, D.V.; Abbott, L.K. Biochars influence seed germination and early growth of seedlings. Plant Soil 2012, 353, 273-287. [CrossRef]

36. Taek-Keun, O.; Shinogi, Y.; Chikushi, J.; Yong-Hwan, L.; Choi, B. Effect of aqueous extract of biochar on germination and seedling growth of lettuce (Lactuca sativa L.). J. Fac. Agric. Kyushu Univ. 2012, 57, 55-60.

37. Fornes, F.; Belda, R.M. Biochar versus hydrochar as growth media constituents for ornamental plant cultivation. Sci. Agric. 2018, 75, 304-312. [CrossRef] 
38. Yeager, T.; Fare, D.; Lea-Cox, J.; Ruter, J.; Bilderback, T.; Gilliam, C.; Niemiera, A.; Warren, S.; Whitewell, T.; White, R. Best Management Practices: Guide for Producing Container-Grown Plants; Southern Nursery Association: Atlanta, GA, USA, 2007.

39. Nieto, A.; Gascó, G.; Paz-Ferreiro, J.; Fernández, J.; Plaza, C.; Méndez, A. The effect of pruning waste and biochar addition on brown peat based growing media properties. Sci. Hortic. 2016, 199, 142-148. [CrossRef]

40. Northup, J. Biochar as a Replacement for Perlite in Greenhouse Soilless Substrates. Master's Thesis, Iowa State University, Ames, IA, USA, 2013.

41. Berek, A.K.; Hue, N.; Ahmad, A. Beneficial use of biochar to correct soil acidity. Food Provid. Hanai Ai 2011, 9 , $1-3$.

42. Vaughn, S.F.; Eller, F.J.; Evangelista, R.L.; Moser, B.R.; Lee, E.; Wagner, R.E.; Peterson, S.C. Evaluation of biochar-anaerobic potato digestate mixtures as renewable components of horticultural potting media. Ind. Crop. Prod. 2015, 65, 467-471. [CrossRef]

43. Dunlop, S.J.; Arbestain, M.C.; Bishop, P.A.; Wargent, J.J. Closing the loop: Use of biochar produced from tomato crop green waste as a substrate for soilless, hydroponic tomato production. HortScience 2015, 50, 1572-1581. [CrossRef]

44. Cho, M.S.; Meng, L.; Song, J.-H.; Han, S.H.; Bae, K.; Park, B.B. The effects of biochars on the growth of Zelkova serrata seedlings in a containerized seedling production system. For. Sci. Technol. 2017, 13, 25-30. [CrossRef]

45. Gu, M.; Li, Q.; Steele, P.H.; Niu, G.; Yu, F. Growth of 'Fireworks' gomphrena grown in substrates amended with biochar. J. Food Agric. Environ. 2013, 11, 819-821.

46. Ruter, J.M. Growth and landscape performance of three landscape plants produced in conventional and pot-in-pot production systems. J. Environ. Hortic. 1993, 11, 124-127.

47. Prendergast-Miller, M.; Duvall, M.; Sohi, S. Biochar-root interactions are mediated by biochar nutrient content and impacts on soil nutrient availability. Eur. J. Soil Sci. 2014, 65, 173-185. [CrossRef]

48. Rellán-Álvarez, R.; Lobet, G.; Dinneny, J.R. Environmental control of root system biology. Annu. Rev. Plant Biol. 2016, 67, 619-642. [CrossRef] [PubMed]

(C) 2019 by the authors. Licensee MDPI, Basel, Switzerland. This article is an open access article distributed under the terms and conditions of the Creative Commons Attribution (CC BY) license (http://creativecommons.org/licenses/by/4.0/). 